\title{
KNOWLEDGE, BELIEFS AND HABITS OF SERBIAN UNIVERSITY STUDENTS REGARDING USAGE OF ANTIBIOTICS - A CROSS-SECTIONAL STUDY OF BIOMEDICAL AND NON-BIOMEDICAL STUDENTS
}

\author{
Nemanja R Kutlesic \\ Faculty of Biosciences and Veterinary Medicine, University of Camerino, Camerino, Italy
}

\begin{abstract}
Proper usage of antibiotics is an often-overlooked subject, leading to a high level of ignorance among youth towards this important topic. The aim of this study was to examine the knowledge, beliefs, and habits of students at Nis University regarding the usage of antibiotics and discover whether an anticipated difference existed between knowledge and habits of biomedical students and that of non-biomedical students. The data were acquired through an online questionnaire that addressed knowledge, beliefs, and habits regarding antibiotics. The study adhered to the principles of the Helsinki declaration. Data were separated into two groups and tested for statistical significance using the Chisquared test. The questionnaire showed that the majority of students (76.86\%) were able to correctly identify bacteria as the main target of antibiotics. More students from non-biomedical faculties thought viral infections could be treated with antibiotics (37.35\% vs. 7.06\% of medical, $p<0.05)$, and identified incorrectly Paracetamol as an antibiotic (42.17\% vs. $8.15 \%$ of medical, $p<0.05)$. However, a similar percentage in both groups $(49.14 \%)$ claimed they interrupted their regimen before the prescribed time, and as much as $67.39 \%$ of biomedical students acquired antibiotics with no prescription. Biomedical students demonstrated much better knowledge and beliefs on antibiotics, however, students from both groups were found to have similar habits regarding the usage. The results are similar to available studies from the developing world. A large percentage of students tampers with antibiotics on their own. Campaigns are necessary to inform students better on the subject.
\end{abstract}

Key words: antibiotics, antibiotic resistance, appropriate use of antibiotics, knowledge, public health, university students.

\section{Introduction}

Proper usage of antibiotics is an important topic often overlooked in high school education, therefore leading to a high level of ignorance among youth. Misuse of antibiotics (regime altering, self-medication, and abuse, missed purpose) can lead to a lowered effect of treatment, ultimately leading to antibiotic resistance [1]. Increased usage of antibiotics has been reported throughout the world, with a growing rate of self-medication [2, 3]. Antibiotics' misuse most commonly leads to antibiotic resistance, which has been estimated to cause 700000 deaths per year; by 2050 this number may rise to 10000000 deaths per year [4].

In relation to this, literature data report that public unawareness level regarding the ineffectiveness of antibiotics in viral diseases was as high as $60 \%$ in the European population in 2001 [5, 6]. Ochoa et al [6] have reported that overuse of antibiotics has been reported in upper respiratory tract infections, regardless of the fact that these infections are mostly viral in origin. Furthermore, a study conducted across Europe showed large rates of self-medication using antibiotics, even in the

Correspondence to: Nemanja R Kutlesic

Faculty of Biosciences and Veterinary Medicine, University of Camerino

Via Macario Muzio 2, 62032 Camerino (MC), Italy

Phone: +393314947655

E-mail: nemanja.kutlesic@studenti.unicam.it

Received March 21 ${ }^{\text {st }}, 2020 /$ Accepted June $21^{\text {st }} 2020$ immediate proximity of Serbia. These numbers include $28 \%$ in Slovenia and $20.5 \%$ in Croatia [7], as well as high levels in other South European countries like Malta, Spain, and Italy [7, 8].

The most worrying statistics is related to the level of knowledge of antibiotics and antibiotic resistance among university students, who are expected to make up the most educated part of the future world's population. Physician's error and antibiotics over-prescription are among the main causes of the development of antibiotic resistance [4]. Therefore, a special emphasis is put on the students of the biomedical profession, as young researchers and clinicians are in a crucial phase of their education where their opinion on the issue should be formed. It has been found difficult to alter their perception once they adopt wrong habits [9].

The objective of this study is to examine the knowledge, beliefs, and habits of students regarding usage of antibiotics and to investigate whether students of medical and similar faculties have a better understanding of the matter in comparison to less relative study courses.

Based on the previous studies [10] and taking into account the curriculum of biomedical faculties, the hypothesis of the study is that biomedical students will demonstrate a better knowledge of the subject and that their habits will be more in compliance with the principles of the rational use of antibiotics. 
According to available research, this study was among the first to investigate and compare the knowledge, habits, and beliefs of medical/pharmaceutical students to students of other branches at the same university. The importance of such a study, besides being one of the pioneers in the field, is to provide a good insight into students' knowledge and attitude on the subject. This can be further used to assess whether campaigns on knowledge improvement are needed and what specific points are to be addressed. Considering that the study focuses on the future academic population of the City of Nis and its broader region, students make up the most important population group whose awareness should be assessed.

\section{Materials and Methods}

Data gathering was performed in collaboration with student representatives from each of the surveyed faculty (cited in Acknowledgements). The main data gathering method was an online survey, in addition to printed questionnaires used in conditions where an online survey could not be implemented.

Prior to completing the online survey, participants gave their informed consent for processing their answers and basic personal details for research purposes. The study was conducted in accordance with the princi- ples of the Helsinki declaration. The questionnaire was completed fully anonymously, and only personal data asked from the participants included age, sex, and faculty affiliation. There was no compensation nor reward offered to participants.

In compliance with the three main domains of the study, the questionnaire was divided into three parts that assessed participants' knowledge, beliefs, and habits, respectively. The questions were designed in compliance with some previous studies conducted in Norway [11], Italy [12], Indonesia [2] and the United Arab Emirates [10].

The survey encompassed a total of 19 questions. The questions were laid out in a manner so that the survey does not resemble a knowledge test, as this could press students to do better and bias the results. Most of the questions asked for a simple Yes/No answer (or Agree/Disagree), however, several questions asked students to choose among given answers (where more answers were possible), and several others asked students to put in an answer on their own (such as the question that asked for an example of an antibiotic). The diverse questions aimed to cover most of the topics related to the consumption of antibiotics.

The questions are enumerated in the following Table 1 , along with the correct (expected, rational) answer highlighted in bold.

Table 1 Questions and possible answers. Correct answers are shaded in bold.

\begin{tabular}{|c|c|c|}
\hline No. & Question & Answer(s) \\
\hline \multicolumn{3}{|c|}{ K N O W L E D G E } \\
\hline 1. & responses possible): & $\begin{array}{c}\text { bacteria, } \\
\text { viruses, fungus }\end{array}$ \\
\hline \multicolumn{3}{|c|}{ 2. What of the following drugs are antibiotics (more responses possible)? } \\
\hline & als, if the daily dosage is respected. & Yes/No \\
\hline 4. & t pain, and common cold. & Yes/No \\
\hline 5. & e illness reappears. & Yes/No \\
\hline 6. 1 & dangerous. & Yes/No \\
\hline
\end{tabular}

6. Taking antibiotics out of dosing regime is not dangerous.

Yes/No

1. I believe that antibiotics can help with most diseases.

2. I believe that taking antibiotics preventively can immunise us against the common flu.

3. I believe that the therapy may be interrupted when the symptoms fade out.

4. I believe that antibiotics have no side-effects.

Agree/Disagree

Agree/Disagree

Agree/Disagree

Agree/Disagree

1. Have you ever acquired antibiotics with no prescription? $\quad$ Yes/No

2. Have you ever acquired antibiotics preventively? $\quad$ Yes/No

3. Have you ever consumed alcohol during your therapy with antibiotics? $\quad$ Yes/No

4. Do you carry an antibiotic when you travel, in case someone falls ill? $\quad$ Yes/No

5. Have you ever interrupted your regime before the time prescribed?

$\begin{array}{ll}\text { 6. Do you always consult your doctor prior to taking antibiotics? } & \text { Yes/No }\end{array}$

7. Do you always inspect the instruction manual and check the expiry date prior to taking an antibiotic? Yes/No

8. Have you ever skipped a dose that you went on to make up for? $\quad$ Yes/No

9. If you take antibiotics on your own, the reasons that you do it for are...
a) You have the antibiotics at home
b) You study medicine (or a relevant faculty, so you are informed
c) someone from you household works in healthcare
d) you've had a good experience with that medicine
e) You do not take them on your own

*: throughout the survey, the common (commercial) name of the antibiotic in Serbia was used, however, in the report, scientific (INN) name is also reported for better understanding of the questions. 
For interpretation, the results have been quantified and represented both in the number of students and in percentile (from the given group - medical or nonmedical students). For the questions where multiple answers were possible, a mode was determined, showing the most frequent option. In order to determine the statistical importance of data obtained and its connection to the studied factor, a common $\chi^{2}$-test for independence (Chi-squared test) was used, where value $\mathrm{p}<0.05$ was considered significant.

\section{Results}

A total of 350 students from Nis University participated in the survey. The students were divided into two main groups. The first group encompasses students of biomedical sciences. This included the Medical Faculty, which includes study programmes Medicine (MD) and Pharmacology, as well as students from the Faculty of Natural Sciences (Biology).

The second group includes students of other faculties, whose study programmes do not have any common points with the topic of antibiotics. These included Faculty of Electronic Engineering, Faculty of Law, Faculty of Economics, Faculty of Philosophy, Faculty of General Engineering, Faculty of Architecture, Faculty of Art and Faculty of Natural Sciences (informatics).

The results have been quantified and divided into three subgroups (knowledge, beliefs, habits), for easier interpretation. There were 184 students from the Medical Faculty and related sciences $(52.57 \%)$, and 166 students from other faculties $(47.43 \%)$. Among the whole number of interrogated students, 123 identified as male $(35.14 \%)$ and 227 as female $(64.86 \%)$. In tables, questions that allowed the participants to give more than one response are denoted with an asterisk (*), to indicate that the overall number of answers is higher than 350 . The group of biomedical students will be referred to as Group A, and the group of students from other faculties will be known as group $\mathrm{B}$.

\section{Knowledge on antibiotics}

Table 2 enumerates answers to the questions regarding students' knowledge on antibiotics. The numbers are given along with percentage in the respective group of data.

Most of the questions have yielded a statistically important difference between the two groups. It is shown that students of both groups have identified bacteria as the main pathogen killed by antibiotics (78.80\% in Group A vs. $74.7 \%$ in group B). However, a significantly larger portion of the group B considered antibiotics useful against viruses $(37.35 \%$ vs.7.06\%, $\mathrm{p}<0.00001)$ and fungi $(18.67 \%$ vs. $7.61 \%, \mathrm{p}=0.002)$.

Similar important differences were found as far as classifying medicines is concerned. A similarly low

Table 2 Results: Knowledge on antibiotics: biomedical students against students of other faculties

\begin{tabular}{|c|c|c|c|c|c|c|c|c|}
\hline Question & \multicolumn{2}{|l|}{ Answers } & All students (350) & \multicolumn{2}{|c|}{ Group A (184) } & \multicolumn{2}{|c|}{ Group B (166) } & \multirow{3}{*}{$\frac{p \text {-value }}{0.363}$} \\
\hline \multirow{6}{*}{$\begin{array}{l}\text { Antibiotics are effective } \\
\text { against... }\end{array}$} & \multirow{2}{*}{ Bacteria } & $\mathbf{Y}$ & $269(76.86 \%)$ & 145 & $(78.80 \%)$ & 124 & $(74.7 \%)$ & \\
\hline & & $\mathbf{N}$ & $81(23.14 \%)$ & 39 & $(21.19 \%)$ & 42 & $(25.3 \%)$ & \\
\hline & \multirow{2}{*}{ Viruses } & $\mathbf{Y}$ & $75(21.43 \%)$ & 13 & $(7.06 \%)$ & 62 & $(37.35 \%)$ & \multirow{2}{*}{$<0.001$} \\
\hline & & $\mathbf{N}$ & $275(78.57 \%)$ & 171 & $(92.94 \%)$ & 104 & $(62.65 \%)$ & \\
\hline & \multirow{2}{*}{ Fungus } & $\mathbf{Y}$ & $45(12.86 \%)$ & 14 & $(7.61 \%)$ & 31 & $(18.67 \%)$ & \multirow{2}{*}{0.002} \\
\hline & & $\mathbf{N}$ & $305(87.14 \%)$ & 170 & $(92.39 \%)$ & 135 & $(81.33 \%)$ & \\
\hline \multirow{12}{*}{$\begin{array}{l}\text { Of the following drugs, } \\
\text { antibiotics are... }\end{array}$} & \multirow{2}{*}{ Brufen } & $\mathbf{Y}$ & $33(9.43 \%)$ & 5 & $(2.72 \%)$ & 28 & $(16.87 \%)$ & \multirow{2}{*}{$<0.001$} \\
\hline & & $\mathbf{N}$ & $317(90.57 \%)$ & 179 & $(97.28 \%)$ & 138 & $(83.13 \%)$ & \\
\hline & \multirow{2}{*}{ Paracetamol } & $\mathbf{Y}$ & $85(24.29 \%)$ & 15 & $(8.15 \%)$ & 70 & $(42.17 \%)$ & \multirow{2}{*}{$<0.001$} \\
\hline & & $\mathbf{N}$ & $265(75.71 \%)$ & 169 & $(91.85 \%)$ & 96 & $(57.83 \%)$ & \\
\hline & \multirow{2}{*}{ Probiotic } & $\mathbf{Y}$ & $29(8.29 \%)$ & 10 & $(5.43 \%)$ & 19 & $(11.45 \%)$ & \multirow{2}{*}{0.042} \\
\hline & & $\mathbf{N}$ & $321(91.17 \%)$ & 174 & $(94.57 \%)$ & 147 & $(88.55 \%)$ & \\
\hline & \multirow{2}{*}{ Sinacillin } & $\mathbf{Y}$ & $279(79.71 \%)$ & 163 & $(88.59 \%)$ & 116 & $(69.88 \%)$ & \multirow{2}{*}{$<0.001$} \\
\hline & & $\mathbf{N}$ & $71(20.29 \%)$ & 21 & $(11.41 \%)$ & 50 & $(30.12 \%)$ & \\
\hline & \multirow{2}{*}{ Bromazepam } & $\mathbf{Y}$ & $\begin{array}{ll}9 & (2.57 \%)\end{array}$ & 1 & $(0.54 \%)$ & 8 & $(4.82 \%)$ & \multirow{2}{*}{0.012} \\
\hline & & $\mathbf{N}$ & $341(97.43 \%)$ & 183 & $(99.46 \%)$ & 158 & $(95.18 \%)$ & \\
\hline & \multirow{2}{*}{ Penicillin } & $\mathbf{Y}$ & $282(80.57 \%)$ & 166 & $(90.22 \%)$ & 116 & $(69.88 \%)$ & \multirow{2}{*}{$<0.001$} \\
\hline & & $N$ & $68(19.43 \%)$ & 18 & $(9.78 \%)$ & 50 & $(30.12 \%)$ & \\
\hline \multirow{2}{*}{\multicolumn{2}{|c|}{$\begin{array}{l}\text { Antibiotics need not be taken in regular intervals, } \\
\text { as long as the daily dosage is respected. }\end{array}$}} & $\mathbf{Y}$ & $48(13.71 \%)$ & 10 & $(5.43 \%)$ & 38 & $(22.89 \%)$ & \multirow{2}{*}{$<0.001$} \\
\hline & & $\mathbf{N}$ & $301(86.00 \%)$ & 174 & $(94.46 \%)$ & 127 & $(76.51 \%)$ & \\
\hline \multirow{2}{*}{\multicolumn{2}{|c|}{$\begin{array}{l}\text { Antibiotics help after all types of cough, throat } \\
\text { pain, and common cold. }\end{array}$}} & $\mathbf{Y}$ & $62(17.71 \%)$ & 12 & $(6.52 \%)$ & 50 & $(30.12 \%)$ & \multirow{2}{*}{$<0.001$} \\
\hline & & $\mathbf{N}$ & $278(79.43 \%)$ & 163 & $(88.59 \%)$ & 115 & $(69.28 \%)$ & \\
\hline \multirow{2}{*}{\multicolumn{2}{|c|}{$\begin{array}{l}\text { Antibiotics can be kept for further usage, if the } \\
\text { illness reappears. }\end{array}$}} & $\mathbf{Y}$ & $116(33.14 \%)$ & 58 & $(31.52 \%)$ & 58 & $(34.94 \%)$ & \multirow{2}{*}{0.399} \\
\hline & & $\mathbf{N}$ & $230(65.71 \%)$ & 126 & $(68.48 \%)$ & 104 & $(62.65 \%)$ & \\
\hline Taking antibiotics out of & g regimen is not & $\mathbf{Y}$ & $16 \quad(4.57 \%)$ & 8 & $(4.35 \%)$ & 8 & $(4.82 \%)$ & \\
\hline dangerous. & & $\mathbf{N}$ & $331(94.57 \%)$ & 175 & $(95.11 \%)$ & 156 & $(93.98 \%)$ & 2 \\
\hline
\end{tabular}

Abbreviations: Y: yes, N: no, Group A: biomedical students, Group B: non-biomedical students 
number of students identified Probiotic as an antibiotic in both groups $(5.43 \%$ vs. $11.45 \%)$. However, all other medicines have been better identified (with a significant difference) by students of the biomedical sciences (group A). Ibuprofen was correctly identified as a nonsteroid anti-inflammatory drug [NSAID] by $97.28 \%$ of participants from group A, whereas $16.87 \%$ of group B identified it as an antibiotic $(\mathrm{p}<0.00001)$. The largest difference was found when it came to identifying Paracetamol (acetaminophen). This drug was classified as an antibiotic by as much as $42.17 \%$ of students from group $\mathrm{B}$, whereas this number drops to $8.15 \%$ among group A $(p<0.00001)$.

Yes-no questions were answered with less discrepancy between the groups. Similar percentages (31.52\% students from A, and $34.94 \%$ of students from B) considered that antibiotics can be kept for future use, and similar percentages (4.35\% of group A vs. $4.82 \%$ of group B) considered that taking antibiotics out of dosing regime is not harmful. However, differences were found in the question regarding the regularity of the dosing regimen. A large portion of group A $(94.46 \%)$ considered that antibiotics must be taken in regular intervals only, whereas this number drops to $76.51 \%$ in group $\mathrm{B}, \mathrm{p}<0.00001$. Another large gap is seen in the question about the effectiveness of antibiotics. They were found useful against all types of common cold and cough by $30.12 \%$ of the group B, whereas as little as $6.52 \%$ of students from the group A considered this statement true, $\mathrm{p}<0.00001$.

\section{Beliefs on antibiotics}

Table 3 enumerates answers to questions about beliefs on antibiotics and their effectiveness. The same notation is kept as in Table 2.

Statistical significance was noted in all four questions related to beliefs about antibiotics. Fewer students from group A believed that antibiotics are helpful with most diseases than in group B $(24.46 \%$ vs. $39.16 \%$, $\mathrm{p}<0.00001)$. A slightly larger number of students from group B thought that antibiotics can be taken to prevent disease $(8.43 \%$ vs. $2.17 \%, p=0.007)$, similarly to the belief in relation to side-effects. Only two students from group A (1.08\%) stated that antibiotics had no side effects, whereas $7.83 \%$ of students from group B have reported such a belief $(\mathrm{p}=0.002)$. However, a significantly larger portion of students from group B believed that the therapy may be interrupted when the symptoms fade out (20.48\% vs. $7.61 \%, \mathrm{p}=0.001)$.

\section{Habits about taking the antibiotics}

Table 4 summarises the results from last nine questions that are related to students' habits when it comes to consuming antibiotics. The notations remain the same as in previous tables.

The two groups have more in common as far as habits of antibiotics' usage is concerned. There was no statistical difference in answers on questions about preventive usage of antibiotics, alcohol consumption during therapy, carrying antibiotics on travels, regime interruption, and consulting a doctor prior to therapy, with the percentages being similar across the range. However, the statistical difference $(p=0.001)$ was observed when it comes to acquiring antibiotics without a prescription. Students from group A have reported this in a larger percentage $(67.39 \%$ vs. $48.19 \%)$. Also, a statistical difference was observed in answers to the question that addresses expiry date verification and the instruction manual. Again, a much larger percentage of students from group A reported reading the manual and verifying the date $(80.43 \%$ vs. $62.05 \%, \mathrm{p}=0.001)$.

The final question, which asks about the reasons for which students take antibiotics on their own, has statistically significant results at $\mathrm{p}<0.00001$. More students from group A listed that it was hard to reach a doctor $(24.46 \%$ vs. $6.63 \%)$ and that they took advice from a family member working in healthcare $(25.00 \%$ vs. $21.69 \%$ ). However, students from group B opted in a larger percent for "I have it at home" and "I had a good experience with the medicine", $30.72 \%$ vs. $25.54 \%$ and $20.48 \%$ vs. $15.22 \%$, respectively, so there was a clear distinction between the answers of the two groups. Note that the percentages account for the part of the students' answer in the whole group of students, not just those who answered this question.

Table 3 Beliefs on antibiotics.

\begin{tabular}{|c|c|c|c|c|c|c|}
\hline Question & & All stu & ents (350) & Group A (184) & Group B (166) & p value \\
\hline \multirow{2}{*}{$\begin{array}{l}\text { I believe antibiotics can help me } \\
\text { with most diseases. }\end{array}$} & A & 101 & $(28.86 \%)$ & $45(24.46 \%)$ & $65(39.16 \%)$ & \multirow{2}{*}{$<0.001$} \\
\hline & $\mathrm{D}$ & 236 & $(67.43 \%)$ & $139(75.54 \%)$ & $97(58.43 \%)$ & \\
\hline \multirow{2}{*}{$\begin{array}{l}\text { I believe that taking antibiotics preventively } \\
\text { can immunise us against the common flu. }\end{array}$} & A & 18 & $(5.14 \%)$ & $4 \quad(2.17 \%)$ & $14(8.43 \%)$ & \multirow{2}{*}{0.007} \\
\hline & $\mathrm{D}$ & 329 & $(91.39 \%)$ & $180(97.83 \%)$ & $149(89.76 \%)$ & \\
\hline \multirow{2}{*}{$\begin{array}{l}\text { I believe that the therapy may be interrupted } \\
\text { when the symptoms fade out. }\end{array}$} & $\mathrm{A}$ & 48 & $(13.71 \%)$ & $14 \quad(7.61 \%)$ & $34(20.48 \%)$ & \multirow{2}{*}{0.001} \\
\hline & $\mathrm{D}$ & 298 & $(82.78 \%)$ & $168(91.39 \%)$ & $130(78.31 \%)$ & \\
\hline \multirow{2}{*}{ I believe that antibiotics have no side-effects. } & A & 15 & $(4.29 \%)$ & $(1.08 \%)$ & $13(7.83 \%)$ & \multirow{2}{*}{0.002} \\
\hline & $\mathrm{D}$ & 331 & $(94.57 \%)$ & $181(98.37 \%)$ & $150(90.36 \%)$ & \\
\hline
\end{tabular}

Abbreviations. A: agree, D: disagree, Group A: biomedical students, Group B: non-biomedical students. NB. Not all the participants have answered the questions. 
Table 4 Results on questions about habits on antibiotics.

\begin{tabular}{|c|c|c|c|c|c|}
\hline \multicolumn{2}{|l|}{$\overline{\text { Question }}$} & All students (350) & group A (184) & group B (166) & $\mathrm{p}$ value \\
\hline \multirow{2}{*}{\multicolumn{2}{|c|}{ Have you ever acquired antibiotics with no prescription? }} & $204(56.67 \%)$ & $124(67.39 \%)$ & $80(48.19 \%)$ & \multirow{2}{*}{0.001} \\
\hline & & $145(41.43 \%)$ & $60(32.61 \%)$ & $85(51.21 \%)$ & \\
\hline \multirow{2}{*}{\multicolumn{2}{|c|}{ Have you ever acquired antibiotics preventively? }} & $15(4.17 \%)$ & $10 \quad(5.43 \%)$ & $5 \quad(3.01 \%)$ & \multirow{2}{*}{0.261} \\
\hline & & $324(92.57 \%)$ & $168(91.30 \%)$ & $156(93.98 \%)$ & \\
\hline \multirow{2}{*}{\multicolumn{2}{|c|}{$\begin{array}{l}\text { Have you ever consumed alcohol during your therapy } \\
\text { with antibiotics? }\end{array}$}} & $74(20.56 \%)$ & $36(19.57 \%)$ & $38(22.89 \%)$ & \multirow{2}{*}{0.412} \\
\hline & & $274(78.29 \%)$ & $148(80.43 \%)$ & $126(75.91 \%)$ & \\
\hline \multirow{2}{*}{\multicolumn{2}{|c|}{$\begin{array}{l}\text { Do you carry an antibiotic when you travel, in case } \\
\text { someone falls ill? }\end{array}$}} & $197(56.29 \%)$ & $101(54.89 \%)$ & $96(57.83 \%)$ & \multirow{2}{*}{0.536} \\
\hline & & $152(43.43 \%)$ & $83(45.11 \%)$ & $69(41.57 \%)$ & \\
\hline \multirow{2}{*}{\multicolumn{2}{|c|}{$\begin{array}{l}\text { Have you ever interrupted your regime before the time } \\
\text { prescribed? }\end{array}$}} & $172(49.14 \%)$ & $87(47.28 \%)$ & $85(51.20 \%)$ & \multirow{2}{*}{0.485} \\
\hline & & $173(49.43 \%)$ & $94(51.09 \%)$ & $79(47.59 \%)$ & \\
\hline \multirow{2}{*}{\multicolumn{2}{|c|}{$\begin{array}{l}\text { Do you always consult your doctor prior to taking } \\
\text { antibiotics? }\end{array}$}} & $211(60.29 \%)$ & $111(60.33 \%)$ & $100(60.24 \%)$ & \multirow{2}{*}{0.987} \\
\hline & & $139(39.71 \%)$ & $73(39.67 \%)$ & $66(39.76 \%)$ & \\
\hline \multirow{4}{*}{\multicolumn{2}{|c|}{$\begin{array}{l}\text { Do you always inspect the instruction manual and check } \\
\text { the expiry date prior to taking an antibiotic? } \\
\text { Have you ever skipped a dose that you went on to make } \\
\text { up for? }\end{array}$}} & $251(71.71 \%)$ & $148(80.43 \%)$ & $103(62.05 \%)$ & \multirow{2}{*}{0.001} \\
\hline & & $94(26.86 \%)$ & $36(19.57 \%)$ & $58(34.94 \%)$ & \\
\hline & & $125(35.71 \%)$ & $64(34.78 \%)$ & $61(36.75 \%)$ & \multirow{2}{*}{0.831} \\
\hline & & $229(63.61 \%)$ & $120(65.22 \%)$ & $109(65.66 \%)$ & \\
\hline \multirow{5}{*}{$\begin{array}{l}\text { If you take antibiotics } \\
\text { on your own, } \\
\text { the reasons that you } \\
\text { do it for are... } \\
\text { (multiple responses) }\end{array}$} & I have it at home & $98(28.00 \%)$ & $47(25.54 \%)$ & $51(30.72 \%)$ & \multirow{5}{*}{$<0.00001$} \\
\hline & $\begin{array}{l}\text { I study medicine (or relevant faculty), } \\
\text { so I am informed }\end{array}$ & $65(18.57 \%)$ & $63(34.24 \%)$ & $2 \quad(1.20 \%)$ & \\
\hline & $\begin{array}{l}\text { Someone from my household works } \\
\text { in healthcare }\end{array}$ & $82(23.43 \%)$ & $46(25.00 \%)$ & $36(21.69 \%)$ & \\
\hline & it's hard to reach a doctor & $56(16.00 \%)$ & $45(24.46 \%)$ & $11 \quad(6.63 \%)$ & \\
\hline & $\begin{array}{l}\text { I had a good experience } \\
\text { with that medicine }\end{array}$ & $62(17.71 \%)$ & $28(15.22 \%)$ & $34(20.48 \%)$ & \\
\hline
\end{tabular}

Abbreviations: Y: yes, N: no, Group A: biomedical students, Group B: non-biomedical students

\section{Discussion}

As mentioned in Introduction, this study is one of the rare few to approach comparatively the subject. The study has found statistically significant differences between the two groups in the sections on knowledge and beliefs. Similar results were reported in the United Arab Emirates [10] where the two groups have been compared, and the hypotheses of the two surveys coincide.

\section{Knowledge on antibiotics}

Students from both groups have correctly identified bacteria as the main pathogen for which antibiotics are used. They have done so with a lower percentage than students from Nepal [13] and Malaysia [14], where almost all participants denoted bacteria correctly. By contrast, students in Serbia have done considerably better than their counterparts in Jordan, where the percent of correct answers was $70.4 \%$ and $29.9 \%$ of medical and nonmedical students, respectively [15].

However, non-biomedical students have identified viruses in a much larger percentage than the ones from the biomedical domain $(37.35 \%$ vs. $7.06 \%)$. These numbers are somewhat better than ones reported in South Jordan [15], where the ratio of medical vs. non-medical stood at $28.1 \%$ vs. $67.2 \%$. The rate was similar in the United Arab Emirates [10], where the percentages were $34.2 \%$ and $69.8 \%$, of medical and non-medical students, respectively. These percentages indicate that students from the Serbian university have a somewhat better knowledge of the ineffectiveness of antibiotics in viral infections. This is supported by studies from Malaysia $[14,16]$ and Italy [17], where $20 \%$ of medical students considered antibiotics effective against viruses.

Similarly, students of biomedical sciences are more aware that time of the dosage regiment needs to be respected to prevent the development of antibiotic resistance, with as low as $5.43 \%$ reporting that antibiotics need not be taken at regular intervals. This percentage is more reassuring than the one reported by a study on medical students from Sudan [18], where $46.1 \%$ reported making-up dosages as frequent.

Students from non-biomedical faculties were found more likely to consider antibiotics helpful against all types of cough and common cold (30.12\% vs. $6.52 \%)$. A completely opposed ratio of the two groups was found in the only similar study in the United Arab Emirates [10], where more medical students were likely to employ antibiotics against cold cough (34.2\%) than non-medical students $(25.2 \%)$. Comparing answers of biomedical students from Nis to the immediate region, one sees that numbers reported in Poland were slightly better, where only $6.6 \%$ of medical students stated having employed antibiotics against the common cold [19]. However, much more worrying data was found in Trinidad and Tobago (35.2\%) [20], South India (22.7\%) [9], and United Arab Emirates (34.12\%) [10]. Besides, a 
multitude of studies conducted in Asia has reported much larger percentages of students of medicine or pharmacology employing antibiotics in this fashion. These include Saudi Arabia (64.2\%) [21], Qatar (62\%) [22], and Sri Lanka (57\%) [23]. This shows that biomedical students from Nis University have a better perception of the subject.

Differently to most questions, a similar number of students from both groups (between 30\% and 35\%) have reported that they keep antibiotics for future usage. Similar numbers have been reported in Sudan [18], and Malaysia [14], without distinction between study courses. Nevertheless, the number of students from Nis who keep antibiotics for future use is lower than the one in Nigeria [24], where $51 \%$ of the general population of university students have admitted doing so.

Finally, when asked to identify antibiotics, biomedical students in Nis were far more successful than their peers from other faculties. Large differences in percentages were reported when it comes to Amoxicillin (marketed as Sinacillin), Bromazepam, Paracetamol, Probioti,c and Ibuprofen (marketed as Brufen). These differences can undoubtedly be explained by the fact that students of biomedical sciences have much more theoretical knowledge on the subject than ones from the other faculties. Compared to a study done in Saudi Arabia [21], students from Serbia from both groups have been more successful in identifying drugs. In Saudi Arabia, as much as $74 \%$ have not been sure about the nature of Paracetamol. In Nis, Paracetamol was incorrectly identified by $42.17 \%$ of non-biomedical and $8.15 \%$ of biomedical students. The largest number of students have identified correctly Bromazepam and Sinacillin (amoxicillin), as the two are among more famous drugs in Serbia. Similar findings were reported in China [25]. Amoxicillin was identified correctly in both groups ( $88.59 \%$ vs. $69.88 \%$ ), with a better percentage than the one reported in the United Arab Emirates [10], where the percentages were $69 \%$ vs. $50.5 \%$ for medical and non-medical students, respectively. Therefore, students from the Serbian university have distinguished better between the commonly used medicines.

In a nutshell, biomedical students have demonstrated a better knowledge of antibiotics than their counterparts from other study courses. This confirms the hypothesis of this survey. When compared with similar studies conducted elsewhere, one concludes that students of Nis University have demonstrated average or slightly better results. This applies also to the studies conducted in the near region, like in Italy and Portugal $[17,26]$. Yet, they need to be educated as far as keeping antibiotics for future use is concerned.

\section{Beliefs}

In all questions regarding students' beliefs on antibiotics, biomedical students have scored better with a statistical significance. This is in compliance with the hypothesis of this research, as the biomedical students should be more aware of the correct usage of antibiotics. In addition, they have done somewhat better than some studies in the proximate region of Southern Europe, such as the one in Italy [17]. In this study, $15 \%$ of students from a biomedical school reported approval of premature interruption of treatment, compared to $7.61 \%$ from Nis. Furthermore, a much lower number of biomedical students from Nis reported that antibiotics had no side-effects $(1.08 \%)$ than in South India, whereby as much as $15.5 \%$ considered antibiotics to be universally safe drugs [9].

Nevertheless, in the group of non-biomedical students, relatively satisfactory answers have been reported. However, it is worrying that as much as $20.48 \%$ consider that therapy may be interrupted as soon as the symptoms fade out, neglecting possible surviving pathogens. Therefore, they appear unaware that, in order to obtain the complete effect of the prescribed medication, the full dose must be taken. This can be explained by the fact that antibiotics often display the desired result before the entire treatment is complete [3, 4]. Similar numbers were reported by studies in developing countries, such as Sudan [18].

\section{Habits}

Despite the fact that the biomedical students were better informed about antibiotics, as seen in the Knowledge section, and that they have demonstrated results that are as good as or even better than those of their peers in comparable countries, the habits seem to be more or less same in both groups.

Statistical difference was found in answers to the question regarding the acquisition of antibiotics with no prescription, where as much as $67.39 \%$ of biomedical students reported doing so, compared to $48.1 \%$ of nonbiomedical students. This can be linked to the fact that the biomedical students may consider themselves informed enough to take the matter in their own hands. Similar numbers were reported in Qatar [22]. However, a much more promising result was noted in Malaysia [16], where only $11.3 \%$ of students from non-biomedical faculties have reported acquisition without a prescription.

Another statistical significance was found in answers to the question on the instruction manual and expiry date. A larger percentage of biomedical students reported that they check them regularly $(80.43 \%)$ in comparison to non-biomedical students $(62.05 \%)$. The rational behaviour is in compliance with a study from Sudan [18].

The reasons that students take the antibiotics on their own are also different between the groups. A part of biomedical students considers themselves informed enough to decide on the usage of antibiotics (34.24\%). Also, a larger percentage of biomedical students have reported it hard to reach a doctor. The numbers show that students from non-biomedical faculties tend to put more faith in their previous experience with the drug. A larger 
percentage $(30.72 \%)$ keeps the antibiotic at home and one- fifth of participants return to the medicine they have had a good experience with. These numbers are more acceptable than those reported in China [25], where as much as $63 \%$ of students kept antibiotics at home. Also, in South Jordan [27], almost a third of interrogated parties reported that they would use antibiotics they already have.

Other questions have yielded no statistical significance. This is different than studies from Jordan [15], and the United Arab Emirates [10], where biomedical students have demonstrated better habits than their counterparts from other faculties. In any case, the general correct response rate moves between $50 \%$ and $60 \%$. Around $60 \%$ report consulting their physician before using the medicines. Similar numbers were found in studies on the general public in Italy and Norway [11, 12], and drastically different to a study from Turkey, where as much as $89 \%$ reported using antibiotics on their own [28], as well as to a study from China [29], where just over a quarter stated they would consult their doctor. Around $55 \%$ of students have reported carrying antibiotics on holidays, implying they might reach out to them without consulting their doctor should they assess the situation as dangerous.

Around $21 \%$ have admitted to using alcohol during the treatment. This demonstrates their awareness of the side effects of alcohol usage during antibiotic therapy which includes inhibition of the drug's effect or even violent physical reactions when combined with certain antibiotics [30]. Numbers from Nis are better than ones reported in a study in Tamil Nadu, where $61.54 \%$ were aware of the fact [31]. Percentages of students who have made up for lost doses is similar (around 35\%), and considerably better than the Sudanese study, where nearly half of the interrogated students reported constant making up for the missed doses [18]. Therefore, it is conclusive

\section{References}

1. Goossens H. Antibiotic consumption and link to resistance. Clin Microbiol Infect 2009; 15:12-15. doi: 10.1111/j.1469-0691.2009. 02725.x

2. Widayati A, Suryawati S, Crespigny CD, Hiller JE. Knowledge and beliefs about antibiotics among people in Yogyakarta City Indonesia: a cross sectional population-based survey. Antimicrob Resist Infect Cont 2012; 1:38. doi: 10.1186/2047-2994-1-38

3. Bell BG, Schellevis F, Stobberingh E, Goossens H, Pringle M. A systematic review and meta-analysis of the effects of antibiotic consumption on antibiotic resistance. BMC Infect Dis 2014; 14:13. doi: 0.1186/1471-2334-14-13

4. Tagliabue A, Rappuoli R. Changing Priorities in Vaccinology: Antibiotic Resistance Moving to the Top. Front Immunol 2018; 9:1068. doi: 10.3389/fimmu.2018.01068

5. Fair, RJ, Tor, Y. Antibiotics and bacterial resistance in the $21 \mathrm{st}$ century. Perspect Medicin Chem 2014; 6:25-64. doi: 10.4137/pmc. s14459

6. Ochoa C, Eiros J, Inglada L, Vallano A, Guerra L. Assessment of antibiotic prescription in acute respiratory infections in adults. The Spanish Study Group on Antibiotic Treatments. J Infect 2000; 41(1):73-83. doi: 10.1053/jinf.2000.0689.

7. Grigoryan L, Burgerhof JGM, Degener JE, Deschepper R, Lundborg CS, Monnet DL, et al. Attitudes, beliefs and knowledge concerning antibiotic use and self-medication: a comparative European study. that students from this Serbian university tend to have similar habits regarding the usage of antibiotics.

Abovementioned numbers show that students from the University of Nis generally have better knowledge than some comparable groups when antibiotics come to question. Still, their practices are not satisfactory, despite their overall acceptable knowledge. A large percentage of the students take antibiotics on their own. Similarly, they seem to decide for themselves when to stop the dosage, with around half of interrogated students from both groups doing so. This means that the overall habits of the students should be improved.

\section{Conclusion}

The study has found that students of biomedical sciences possess better theoretical knowledge on the subject of antibiotics and their usage and effectiveness. In addition, their beliefs seem to be more rational. This is generally similar to studies conducted around the world. However, habits of the students are mostly the same across the range, without extensive linkages to their study course (with the exception of the acquisition of antibiotics without a prescription and checking the instruction manual of the drug). In general, percentages regarding their habits can be worrying in relation to the length of the treatment course and should be ameliorated with a campaign to better inform the students.

Acknowledgements: The author acknowledges the work of following students from the University of Nis regarding distribution of the survey: Jovanovic Aleksandra, Stojanovic Jovana, Zivkovic Mila (Medical Faculty, University of Nis); Aleksic Petar, Filipovic Irina (Faculty of Philosophy, University of Nis); Pavlovski Aleksandar (Faculty of Electronic Engineering, University of Nis).

Pharmacoepidemiol Drug Saf 2007; 16(11):1234-1243. doi: 10.1002/ pds. 1479 .

8. Grigoryan L, Monnet D, Haaijer-Ruskamp F, Bonten M, Lundborg $\mathrm{S}$, Verheij T. Self-medication with antibiotics in Europe: a case for action. Curr Drug Saf 2010; 5(4):329-332. https://doi.org/10.2174/ 157488610792246046

9. Afzal Kahn AK, Banu G, Reshma KK. Antibiotic resistance and usage-A Survey on the knowledge, attitude, perceptions and practices among the medical students of a Southern Indian Teaching Hospital. J Clin Diagn Res 2013; 7(8):1613-1616. doi: $10.7860 / \mathrm{jcdr} / 2013 / 6290.3230$

10. Jairoun A, Hassan N, Ali A, Jairoun O, Shahwan M, Hassali M. University students' knowledge, attitudes, and practice regarding antibiotic use and associated factors: a cross-sectional study in the United Arab Emirates. Int J Gen Med 2019; 12:235-246. doi: 10.2147/ijgm.s200641

11. Waaseth M, Adan A, Røen IL, Eriksen K, Stanojevic T, Halvorsen $\mathrm{KH}$, et al. Knowledge of antibiotics and antibiotic resistance among Norwegian pharmacy customers - a cross-sectional study. BMC Public Health 2019, 19(1):66. doi: 10.1186/s12889-019-6409-x

12. Napolitano F, Izzo MT, Giuseppe GD, Angelillo IF. Public knowledge, attitudes, and experience regarding the use of antibiotics in Italy. PLoS ONE 2013; 8(12):e84177. doi: 10.1371/journal.pone. 0084177 
13. Shrestha, R. Knowledge, attitude and practice on antibiotics use and its resistance among medical students in a tertiary care hospital. JNMA J Nepal Med Assoc 2019; 57(216):74-79. doi: $10.31729 /$ jnma.4224

14. Kanneppady S, Oo A, Lwin O, Al-Abed A-A A, Kanneppady S. Knowledge, attitude, and awareness of antibiotic resistance among medical students. Arch Med Health Sci 2019; 7(1):57-60. doi: 10.4103/amhs.amhs_104_18

15. Suaifan GARY, Shehadeh $\bar{M}$, Darwish DA, Al-Ijel H, Yousef AM, Darwish RM. A cross-sectional study on knowledge, attitude and behavior related to antibiotic use and resistance among medical and non-medical university students in Jordan. Afr $\mathbf{J}$ Pharm Pharmacol 2012; 6(10):763-770. https://academicjournals. org/article/article1380876463_Suaifan\%20et\%20al.pdf

16. Haque M, Rahman NAA, Mckimm J, Sartelli M, Kibria G., Islam, MZ, et al. Antibiotic use: A cross-sectional study evaluating the understanding, usage and perspectives of medical students and pathfinders of a Public Defence University in Malaysia. Antibiotics (Basel) 2019; 8(3):154. doi: 10.3390/antibiotics8030154

17. Scaioli G, Gualano MR, Gili R, Masucci S, Bert F, Siliquini R. Antibiotic use: A cross-sectional survey assessing the knowledge, attitudes and practices amongst students of a school of medicine in Italy. Plos One 2015; 10(4):e0122476. doi: 10.1371/journal.pone. 0122476

18. Sunusi LSA, Awad MM, Hassan NM, Isa CA. Assessment of knowledge and attitude toward antibiotic use and resistance among students of International University of Africa, Medical Complex, Sudan. Glob Drugs Therap 2019; 4(2). doi: 10.15761/gdt.1000171

19. Sobierajski T, Wanke-Rytt M, Mazińska B, Karpierz, K, Hryniewicz $\mathrm{W}$. The knowledge on antibiotics and antimicrobial resistance among Polish medical students. Eur J Public Health 2019; 29(S4). doi: 10. 1093/eurpub/ckz186.517

20. Ahmad A, Khan MU, Patel I, Maharaj S, Pandey S, Dhingra S. Knowledge, attitude and practice of B.Sc. Pharmacy students about antibiotics in Trinidad and Tobago. J Res Pharm Pract 2015; 4(1):37-41. doi: 10.4103/2279-042X.150057

21. Zaidi SF, Alotaibi R, Nagro A, Alsalmi M, Almansouri H, Khan MA, et al. Knowledge and attitude towards antibiotic usage: A questionnaire-based survey among pre-professional students at King Saud bin Abdulaziz University for Health Sciences on Jeddah
Campus, Saudi Arabia. Pharmacy (Basel) 2020, 8(1):5. doi: 10.3390/ pharmacy 8010005

22. Aljayyousi GF, Abdel-Rahman ME, Heneidy AE, Kurdi R, Faisal E. Public practices on antibiotic use: A cross-sectional study among Qatar University students and their family members. Plos One 2019; 14(11):e0225499. doi: 10.1371/journal.pone.0225499

23. Sakeena MHF, Bennett AA, Jamshed S, Mohamed F, Herath DR, Gawarammana I, et al. Investigating knowledge regarding antibiotics and antimicrobial resistance among pharmacy students in Sri Lankan universities. BMC Infect Dis 2018; 18(1):209. doi: 10.1186/s12879018-3107-8

24. Igbeneghu OA. Knowledge and practices in the use of antibiotics among a group of Nigerian university students. Int J Infect Control 2013; 9(1). doi: 10.3396/ijic.v9i1.10539

25. Wang X, Peng D, Wang W, Xu Y, Xudong Z, Hesketh T. Massive misuse of antibiotics by university students in all regions of China: implications for a national policy. Int J Antimicrob Agents 2017; 50(3):441-446. doi: 10.1016/j.ijantimicag.2017.04.009.

26. Azevedo MM, Pinheiro C, Yaphe J, Baltazar F. Portuguese students' knowledge of antibiotics: a cross-sectional study of secondary school and university students in Braga. BMC Public Health 2009; 9(1):359. doi: 10.1186/1471-2458-9-359

27. Nawafleh H, Momani MA, Hadid LA, Amarat WA. Misuse of antibiotic therapy among university community in South Jordan Health Sci J 2017; 10(6):478. doi: 10.21767/1791-809X.1000478

28. Buke C, Hosgor-Limoncu M, Ermertcan S, Ciceklioglu M, Tuncel M, Köse $\mathrm{T}$, et al. Irrational use of antibiotics among university students. J Infect 2005; 1(2):135-139. doi: 10.1016/j.jinf.2004.12.001

29. Peng D, Wang X, Xu Y, Sun C, Zhou X. Antibiotic misuse among university students in developed and less developed regions of China: a cross-sectional survey. Global Health Action 2018; 11(1):1496973. doi: 10.1080/16549716.2018.1496973

30. Steckelberg JM. Can I drink alcohol while taking antibiotics? Mayo Clinic, 2018. https://www.mayoclinic.org/healthy-lifestyle/consumerhealth/expert-answers/antibiotics-and-alcohol/faq-20057946

31. Arul Prakasam KC, Senthil Kumar N, Ramesh J. Students' knowledge of antibiotics: a cross-sectional study of students in Tamil Nadu. Int J Pharm and Pharm Sci 2011; 3(1):232-233. https://innovareacademics.in/journal/ijpps/Vol3Issue1/1100.pdf 